\title{
Emprego doméstico e mudança social Reprodução e heterogeneidade na base da estrutura ocupacional brasileira
}

\author{
Márcia Lima* \\ https://orcid.org/0000-0003-2923-8445 \\ lan Prates* \\ https://orcid.org/0000-0002-9147-7116
}

Introdução

Segundo relatório da OIT, havia no ano de 2010 ao menos 52 milhões e seiscentos mil empregados domésticos no mundo. Este número é maior do que o total de pessoas empregadas em países como o México, maior que a população da África do Sul e corresponde a 3,6\% do total de empregados remunerados no mundo. $\mathrm{Na}$ América Latina e Caribe os empregos domésticos correspondem a 11,9\% do total dos empregados remunerados. Se considerarmos apenas as mulheres, esses percentuais chegam a $26,6 \%$ nesta e a $7,5 \%$ no mundo.

Diante de números tão impressionantes, resta-nos perguntar: por que a atividade exercida por essas trabalhadoras é nomeada como trabalho invisível em tantos estudos e análises? A resposta envolve a articulação de ao menos quatro importantes categorias fundamentais para compreender desigualdades: classe, raça, gênero e condição de migrante/imigrante. Essas categorias são analisadas na obra de Charles Tilly (1998) sobre a persistência das desigualdades constituídas de forma binária, pois afinal quando falamos de desigualdades estamos tratando de um fenômeno relacional. Estar em condição desigual significa necessariamente considerarmos desigual em relação a quem e em que dimensão.

\footnotetext{
* Universidade de São Paulo, São Paulo, Brasil.
} 
O presente artigo se inspira em dois momentos recentes da história do Brasil: a Proposta de Emenda Constitucional n. 72 de 2 de abril de 2013, que ampliou os direitos trabalhistas das trabalhadoras domésticas e os processos em tramitação, bem como as recentes propostas de reforma da Previdência e aprovação da lei da terceirização - que afetarão os trabalhadores mais frágeis do mercado de trabalho, em especial essa categoria. A conexão entre esses episódios se dá pelo fato de que as últimas reformas surgem justamente no momento em que essa categoria começava a vislumbrar um maior reconhecimento de sua atividade no mercado e nas relações de trabalho, mas é então recolocada numa situação de extrema vulnerabilidade.

Considerando este cenário, o objetivo do presente artigo é analisar mudanças no perfil dos empregados domésticos (2002-2012), observando não apenas as alterações pontuais na legislação que antecedeu a PEC das domésticas, mas também as transformações sociais ocorridas na base da pirâmide social brasileira que podem ter contribuído para novas possibilidades e mudanças ocupacionais das mulheres que compõem o perfil das empregadas domésticas no Brasil ${ }^{1}$. Na primeira parte do artigo será discutido, à luz da bibliografia sobre o tema, o lugar do emprego doméstico nos estudos sobre gênero e raça, procurando destacar seus principais aspectos. $\mathrm{Na}$ segunda parte do artigo serão apresentados os dados recentes sobre emprego doméstico, caracterizando o perfil e o padrão das mudanças. A terceira e última parte traz alguns exercícios estatísticos que captam de forma mais específica as transformações desse grupo. Para isso utilizaremos as análises de clusters, buscando identificar uma tipologia do emprego doméstico no Brasil e suas transformações recentes.

Nesta introdução faremos uma breve discussão sobre os discursos em torno da PEC das Domésticas por dois motivos. Em primeiro lugar, temos o propósito de demonstrar qual a representação e o lugar do emprego doméstico na sociedade brasileira. Em segundo lugar, queremos demonstrar que esta PEC nada mais fez do que ampliar o escopo dos trabalhadores domésticos, garantindo-lhes um conjunto de direitos dos quais eram privados, equiparando os direitos trabalhistas entre os trabalhadores domésticos e os demais trabalhadores urbanos e rurais.

A PEC das domésticas afetou basicamente dois aspectos cruciais da subordinação imposta a essa categoria: a regulação da hora extra e do trabalho noturno, situação que afeta as empregadas que dormem no trabalho. A negativa reação identificada numa parte da população viria a engrossar um conjunto de críticas contra o modelo

1. Como a PEC é de 2013, acreditamos que PNAD-2014 ainda não reflita um possível impacto dessa legislação. No escopo deste texto tomamos a PEC como referência devido a sua repercussão e aos novos marcos legais de regulamentação dessa ocupação. A análise empírica deste artigo procura demonstrar qual o cenário e o perfil das domésticas ao longo da primeira década deste século e em que quadro essa proposta foi implantada. 
de políticas sociais que estavam sendo implantadas no país. Um dos aspectos que nos chamaram atenção no debate contra a PEC (matérias de jornais, relatos em blogs e em redes sociais) foi o discurso contra os possíveis limites que essas novas regras imporiam às relações de trabalho no âmbito doméstico. Ou seja, a relação patrão-patroa/empregada/o doméstica/o não deve ser legislada por ser vista como algo da esfera privada ${ }^{2}$. Dois relatos para ilustrar.

Selecionamos os artigos de colunistas de dois grandes jornais de circulação nacional, $O$ Globo e Folha de S.Paulo. O artigo do jornalista e escritor Guilherme Fiuza, publicado no jornal $O$ Globo (13/4/2013), desqualifica a lei e a compara a outros direitos recém-adquiridos pela população mais pobre do país, tratando esta regulação como mais um desmando do governo. Segundo ele, a PEC desqualifica a responsabilidade individual e os bons costumes.

Agora o país comemora a Lei Áurea das domésticas, com ódio e nojo aos patrões. Eles tiveram sorte, porque não apareceu nenhum revolucionário propondo guilhotina em caso de atraso do $13^{\circ}$. [...]

É esse país que baba de orgulho diante da PEC das domésticas, jurando que está assistindo a uma revolução trabalhista. É típico das sociedades culturalmente débeis acharem que legislar sobre tudo é passaporte civilizatório. É um país que não acredita nos seus acordos, no que é instituído a partir da responsabilidade individual, do bom senso e dos bons costumes (Fiuza, 2013, p. 1).

Parece que o colunista desconhece a altíssima taxa de informalidade do serviço doméstico no Brasil e que o rendimento médio das domésticas do país é inferior ao salário mínimo. Ou seja, não há acordos, responsabilidades individuais nem bons costumes, mas sim velhos hábitos arcaicos de herança escravista que marcam a submissão.

A colunista Danuza Leão também escreve um artigo sobre o tema - que ela considerava "seu assunto favorito" -, narrando a história de um casal rico que tem duas empregadas há quinze anos, que dormem no emprego. Ela faz o seguinte relato:

Quando veio a PEC, a dona da casa - que não suporta a ideia de ter um livro de ponto em casa, e ao mesmo tempo quer ter o direito de pedir um chá às 10 horas da noite - fez as contas com o contador, soube o quanto lhe custaria pagar as horas extras, e chamou as duas para conversar. [...]

2. Essa ideia do empregado doméstico como um bem do domićlio fica evidente no Critério de Classificação Econômica utilizado pela Associação Brasileira de Empresa de Pesquisa, segundo o qual o empregado doméstico é uma das variáveis de composição de bens do domicílio: http://www.abep.org/ criterio-brasil. 
Tenho a impressão que o governo está interferindo um pouco mais do que o tolerável na relação entre empregado e empregador no trabalho doméstico (Leão, 2013, p. 1).

Ou seja, a prerrogativa de pedir um chá às dez horas da noite deve ser mantida, porém não regulada. Não havia sujeitos de direitos do outro lado e a PEC procura romper com a lógica naturalizada do abuso que, justamente por ser naturalizada, não traz constrangimento ao ser enunciada. O local de trabalho de uma parcela dos empregados domésticos é, durante a semana, também seu local de moradia. Sua presença constante o coloca na posição de estar sempre à disposição do patrão ou da patroa fazendo com que essa relação se torne altamente personalista e sujeita a regras próprias. E é justamente no momento em que alguma das partes se encontra em posição fragilizada que o direito deve exercer o papel tanto de proteção contra abusos, como de reversão dos padrões simbólicos vigentes.

Havia também um discurso que apontava que a elevação dos custos envolvidos na contratação de trabalhadores domésticos poderia prejudicá-los com o risco de demissão, aumentando o desemprego. Como veremos neste texto, entre $2002 \mathrm{e}$ 2012 houve uma redução significativa de empregadas domésticas, em especial nas faixas mais jovens, assim como um aumento da escolaridade desses trabalhadores, demonstrando que a redução do tamanho do grupo estaria relacionada à abertura de outras oportunidades ou a uma dedicação integral aos estudos.

Esses casos indicam o tom do debate no momento da aprovação da PEC e colocam ênfase sobre a fragilidade histórica desta categoria de trabalhadores, sempre vista como o segmento mais inferiorizado do mercado de trabalho.

O segundo motivo de tratarmos deste tema da PEC foi o fato de boa parte das pessoas envolvidas naquele debate público demonstrarem um desconhecimento ou ao menos não se referirem ao fato de que emprego doméstico no Brasil é regulamentado desde 1972. E já foi uma regulamentação tardia se considerarmos que os direitos trabalhistas no Brasil já haviam sido discutidos fazia décadas. Vale lembrar esta primeira regulamentação, que definiu o emprego doméstico da seguinte forma:

Considera-se empregado(a) doméstico(a) aquele(a) maior de 18 anos que presta serviços de
natureza contínua (frequente, constante) e de finalidade não lucrativa à pessoa ou à família, no
âmbito residencial destas. Assim, o traço diferenciador do emprego doméstico é o caráter não
econômico da atividade exercida no âmbito residencial do(a) empregador(a) (Brasil, 1972).

Essa descrição deixa claro que a principal diferença entre o trabalhador doméstico e os demais trabalhadores é a característica da atividade, ou seja, seu caráter não econômico. Desde então, a aquisição de direitos por esta categoria tem sido 
conquistada a duras penas, por força do crescimento da sua forma de organização e por mudanças legais implementadas pelo estado brasileiro.

A Constituição Federal de 1988, que regulamentou direitos dos trabalhadores urbanos e rurais, concedeu novos benefícios aos empregados domésticos, mas ainda permanecendo com um terço dos direitos dos demais trabalhadores. Esta constituição assegurou: salário mínimo; irredutibilidade salarial; décimo terceiro salário; repouso semanal remunerado; gozo de férias anuais remuneradas; licença à gestante, sem prejuízo do emprego e do salário, com duração de 120 dias; licença-paternidade; aviso-prévio; aposentadoria e integração à Previdência Social.

Em 2006 foi editada uma lei que alterou a lei de 1972 e incorporou benefícios previstos na Constituição de 1988: os(as) trabalhadores(as) domésticos(as) adquiriram direito a férias de trinta dias, estabilidade para gestantes, direito aos feriados civis e religiosos, além da proibição de descontos de moradia, alimentação, vestuário e produtos de higiene pessoal utilizados no local de trabalho. Outra mudança significativa para incrementar a formalização dos vínculos dos empregados domésticos foi a dedução no Imposto de Renda Pessoa Física de 12\% do valor do recolhimento referente a um salário mínimo mensal de um(a) empregado(a) doméstico(a), incluídas as parcelas de décimo terceiro salário e um terço de férias.

Em síntese, os esforços de submeter o trabalho doméstico a regras trabalhistas não são recentes. Entretanto, o que estudos sobre o tema e as estatísticas sobre mercado de trabalho vêm demonstrando é a baixa adesão dos empregadores a essas regras.

A ideia de invisibilidade do trabalho doméstico revela tanto suas atividades cotidianas como também o seu reconhecimento, mantendo-o predominantemente informal, mal remunerado, com cargas horárias extensas e sem a devida compensação.

\section{Articulando raça e gênero: o lugar do emprego doméstico na reprodução das desigualdades}

A abordagem do tema do emprego doméstico tanto na perspectiva nacional quanto internacional tem sido caracterizada por uma agenda intelectual transversal que sintetiza analiticamente a interface entre raça, gênero, classe e nacionalidade ou naturalidade - a depender do país investigado. Há ainda uma diversificação nos temas tratados, que marca as especificidades de cada sociedade investigada.

Estas vão desde o aspecto mais micro, como as relações cotidianas, até a participação dos governos nos esforços de regulação, passando pelo debate das organizações das domésticas. No cenário internacional, o tema sempre teve como questão a participação das mulheres imigrantes, primeiro nos Estados Unidos e posteriormente na Europa. No caso americano, mais especificamente, há uma mudança desse perfil com 
o aumento do número de mulheres negras americanas nesta ocupação (Burnham e Theodore, 2012).

No Brasil, este tema começou a ser sistematizado no final dos anos 1970 no bojo dos debates sobre emprego feminino ${ }^{3}$. O trabalho de Heleieth Saffioti (1978), Emprego doméstico e capitalismo, é um marco na literatura sobre o tema. Nesse trabalho, a autora utiliza dados do censo de 1970 ao mesmo tempo que desenvolve uma pesquisa no município de Araraquara com empregadas, patroas e "potenciais" patroas (pessoas que desejavam contratar um empregado doméstico). Segundo a autora, que se pauta em uma abordagem marxista, a empregada doméstica é "vítima de uma exploração mediada pela exploração típica do modo de produção capitalista. Ela serve ao sistema na medida em que cria as condições para a sua reprodução" (Saffioti, 1978, p. 196). A questão do trabalho doméstico não considerado trabalho produtivo contribui para uma invisibilidade do tema, que foi sendo, aos poucos, desconstruída por conta do tamanho deste grupo na força de trabalho. Nesse sentido, as abordagens sobre o emprego doméstico passaram a ser articuladas aos estudos sobre a estrutura do mercado de trabalho brasileiro, principalmente nos debates sobre qualificação da mão de obra e crescimento do setor de serviços, aos estudos sobre emprego feminino, e muito fortemente à agenda de estudos sobre desigualdades raciais (Silva e Lima, 1993; Rezende e Lima, 2004).

É possível organizar os estudos sobre emprego doméstico a partir de diferentes dimensões, que vão desde a abordagem macro até observações de situações de interação e relatos. Optamos por apresentar aqui três conjuntos de temas sobre o emprego doméstico, assumindo não ser uma classificação exaustiva das possibilidades de tratamento do tema, mas que contribui para contextualizar o recorte empírico proposto.

Um primeiro conjunto de estudos refere-se aos aspectos mais estruturais, que fazem uso das técnicas quantitativas de investigação. São estudos que procuram fornecer o perfil desta ocupação assim como suas mudanças no tempo. Tais estudos começaram a se destacar quando se ampliaram as análises sobre o crescimento da participação feminina no mercado de trabalho brasileiro em função dos processos de urbanização e industrialização.

Uma importante análise que reconhece a segmentação social dessa expansão é o trabalho de Carlos Hasenbalg e Nelson do Valle Silva (1988). Os autores analisaram a estrutura setorial de emprego no Brasil entre 1960 e 1980, observando que o dinamismo na geração de novos postos de trabalho era fortemente segmentado por sexo. O setor da indústria tornou um emprego fortemente masculino com uma concentração dos mais pobres na indústria de construção civil. A mão de obra femi-

3. Uma boa revisão desta bibliografia sobre emprego doméstico está em Ávila (2009). 
nina ingressou majoritariamente nos serviços de comércio de mercadorias, consumo coletivo (saúde e educação) e prestação de serviços. As mulheres provenientes das classes mais pobres se dirigem para a prestação de serviços e para os empregos ligados à produção na indústria, enquanto que as mulheres de classe média para os serviços de produção e de consumo coletivo, devido aos seus melhores níveis educacionais. Essas transformações foram decisivas para a alocação diferenciada das mulheres no mercado de trabalho segundo sua condição social e racial (Hasenbalg e Silva, 1988).

Esses estudos sempre foram unânimes em destacar que essa ocupação se distingue das demais no interior do mercado de trabalho. Em relação às características dos empregados, são majoritariamente mulheres, negras, com reduzida escolaridade e mais jovens. Em relação às características do posto de trabalho, comparado aos demais, o emprego doméstico é altamente informal, com jornadas de trabalho mais longas, salários mais baixos (inclusive com média salarial abaixo do mínimo). Entretanto, as investigações de caráter longitudinal (ao menos desde os anos 1990) têm observado algumas tendências: redução da participação das mais jovens, um pequeno crescimento da formalização e melhoria do nível educacional (Bruschini e Lombardi, 2000; Brites e Picanço, 2014).

Bruschini e Lombardi, analisando o emprego feminino nos anos 1990, identificam um fenômeno de bipolarização: um polo de empregos mais qualificados como o das profissionais liberais; e outro de ocupações de menor qualificação, como o serviço doméstico. Em relação aos profissionais liberais, as autoras observaram que houve um crescimento da participação de mulheres em ocupações cuja principal característica era a predominância masculina. No polo oposto, o foco da análise foi no emprego doméstico. Elas notaram que, embora existisse uma sobrerrepresentação das mulheres negras no serviço doméstico em geral, essa característica era mais marcante entre as mais jovens. Mas há um aspecto importante que marca a construção dessa bipolaridade e constitui um elo entre esses polos. É a saída das mulheres escolarizadas e de classes médias e altas para o mercado de trabalho que cria a demanda por trabalhadoras domésticas (Bruschini e Lombardi, 2000).

O artigo de Brites e Picanço (2014) discute, através de abordagem quantitativa e qualitativa, a questão da reprodução, reafirmando este traço perverso e ambíguo que marca o emprego doméstico: libera as mulheres para o mercado de trabalho e retém as mais pobres neste setor que é, em geral, de baixo rendimento e com baixa escolarização. Um aspecto importante dos trabalhos mais recentes é justamente chamar a atenção para as mudanças ocorridas. No que tange a esse aspecto, utilizando dados das PNADs de 1993 e 2011, as autoras chamam atenção para um fenômeno relevante que é a redução da participação das mulheres mais jovens (considerando a idade em que começaram a trabalhar), um fenômeno mais recente e altamente 
positivo. Em 1993, 70\% das empregadas domésticas começaram a trabalhar com 14 anos de idade ou menos, em 2011 esse percentual era 51,2\%.

A nota técnica do Ipea sobre emprego doméstico, de autoria de Luana Pinheiro, Natália Fontoura e Cláudia Pedroza (2012), destaca que, além da mudança do perfil etário, houve uma pequena expansão de acesso aos direitos. Entre 1995 e 2009, os dados analisados demonstram o crescimento da participação de empregadas diárias em detrimento das mensalistas e o crescimento da proporção com carteira assinada, embora a formalização ainda seja muito baixa. Outro dado apresentado foi a redução do número de horas trabalhadas por semana. Vale salientar que são as empregadas mensalistas com carteira assinada que trabalham mais horas por semana e que apresentaram menor redução de jornada semanal (Pinheiro, González e Fontoura, 2012).

Um segundo conjunto de estudos tem tratado das formas de mobilização das empregadas domésticas, com enfoque sobre os sindicatos e o levantamento sobre a atuação de organismos internacionais voltados para a questão, em especial a Organização Internacional do Trabalho (OIT).

O relatório da OIT publicado em 2010, Trabalho doméstico no Brasil: rumo ao reconbecimento institucional, destaca que esta ocupação é marcada por relações precárias de trabalho, com pouco reconhecimento governamental e baixíssima regulamentação. Vale lembrar que a OIT dedicou, nas conferências internacionais do trabalho de 2010 e 2011, rodadas de discussões sobre o tema do trabalho decente para os trabalhadores domésticos. A OIT aprovou em 2011 uma recomendação que veda qualquer discriminação entre trabalhadores domésticos e os demais trabalhadores. O Brasil ainda não ratificou essa recomendação, embora tenha adotado alguns avanços como o FGTS e seguro-desemprego (ainda que facultativo), além da PEC das domésticas relatada anteriormente. Considerando o perfil das trabalhadoras (carteira assinada, número de horas trabalhadas), o estudo do Ipea faz uma simulação de gastos e demonstra que a equiparação com os direitos dos demais trabalhadores não traria grandes onerações aos empregadores. No caso das trabalhadoras que já possuem carteira assinada, os custos envolvidos com pagamento de FGTS aumentariam em $8,0 \%$. Levando em conta a média do número de horas trabalhadas, a simulação demonstra que este seria o custo mais alto para o empregador (39,0\%). Entretanto, pessoas que trabalham mais de 44 horas semanais devem ser remuneradas por isso, e esse é um ponto importante da PEC, que procura extinguir o trabalho extra não devidamente remunerado.

Considerando este tema da mobilização por direitos, há outro conjunto de estudos que se dedicam justamente a entender as dificuldades de organização das domésticas, assim como a importância dos pequenos avanços da paulatina regulação de direitos trabalhistas. Um primeiro aspecto a destacar é que, ao menos nas áreas 
metropolitanas, nota-se um crescimento da formalização devido ao maior acesso à informação sobre os direitos trabalhistas, no qual as organizações das domésticas têm um papel importante.

Joaze Bernardino-Costa, em seu estudo sobre empregadas domésticas e sindicalização, utiliza os conceitos de colonialidade do poder e interseccionalidade para tratar da conquista legal das trabalhadoras domésticas a partir de seu protagonismo e ativismo. De acordo com o autor, o primeiro sindicato de trabalhadoras domésticas foi criado na década de 1930 por Laudelina de Campos Melo. Isso mostra que os esforços de reconhecimento legal e visibilização são antigos e constantes. Apesar das dificuldades, os sindicatos, segundo ele, "podem ser vistos como espaço de ruptura com o isolamento intramuros vivenciado pelas trabalhadoras, portanto, ruptura com as relações hierarquizadas vividas no interior da casa dos empregadores" (Bernardino-Costa, 2015, p. 155).

Segundo o levantamento de Pinheiro, Fontoura e Pedroza (2012), a sindicalização das trabalhadoras domésticas é muito baixa. Baseados nos dados do IBGE, eles apontam que apenas 2,0\% das trabalhadoras domésticas, ou aproximadamente 133,7 mil mulheres, eram filiadas a algum sindicato reconhecido pelo Ministério do Trabalho ou registrado em cartório como tal.

Dominique Vidal (2009) discute a importância dos avanços regulatórios do emprego doméstico, considerando que, embora o marco jurídico não suprima a dominação, a ampliação do acesso aos direitos melhora as condições de trabalho e diminui o poder da relação pessoal.

Um terceiro conjunto de investigações versa sobre aspectos cotidianos do emprego doméstico. São estudos de abordagem qualitativa que em geral focam na especificidade das condições de trabalho. São pessoas remuneradas por um trabalho que se realiza no âmbito privado, cuja baixa regulação as coloca vulneráveis a regras pessoais e abusos. Além disso, essas relações são construídas entre mulheres, patroas e empregadas. Ou seja, o serviço doméstico revela também a faceta de gênero da gestão do espaço doméstico. São relações mediadas por tensões em torno das regras cotidianas, afetos marcados por hierarquias (em especial em ambientes com crianças), assim como por grande dose de preconceito e estigmas relacionados à convivência no espaço doméstico: acusações de roubo, restrições alimentares, uso do espaço marcado pela configuração da exclusão e do confinamento. Outro ponto bastante destacado por alguns estudos se refere ao fato de que as relações são fortemente mediadas pela posição social dos seus patrões (Rezende e Lima, 2004; Brites, 2007; Angelin e Truzzi, 2015).

Angelin e Truzzi desenvolveram um estudo sobre o trabalho doméstico remunerado entre adolescentes na cidade de São Carlos, considerando a heterogeneidade tanto dos empregadores quanto das empregadas. Dois grupos de patroas foram 
analisados: as da classe trabalhadora e as de classe média alta. Em relação às empregadas adolescentes, o estudo destaca que há aquelas que buscam emprego para obter alguma autonomia de renda, enquanto outras necessitam ingressar precocemente no mercado de trabalho. Essa diferenciação talvez permita uma maior liberdade para as adolescentes em permanecer ou não no trabalho, que deve ser visto como algo temporário, conciliado com o estudo. Os autores apontam que a classe social das patroas é um diferenciador importante na construção dessas relações. Com os patrões mais pobres, menos conflito e vínculos mais afetivos; com os patrões de classe média alta, mais conflitos e relações mais formais.

A pesquisa etnográfica apresentada no artigo de Brites e Picanço (2014) analisa a família de empregadoras e de empregadas domésticas demonstrando como essa ocupação afeta a vida das patroas, das empregadas e do entorno das empregadas domésticas. No caso das famílias das empregadas domésticas, encontra-se uma maior quantidade daquelas chefiadas por mulheres e maior participação da família estendida.

O estigma dessa ocupação se reflete na percepção das próprias empregadas domésticas, que temem o confinamento nessa ocupação. A antropóloga Caetana Damasceno numa pesquisa sobre gênero, raça e mercado de trabalho ouviu de algumas entrevistadas a expressão "sujar a carteira”. As entrevistadas, em especial as mais novas, alegavam que muitas não queriam assinar a carteira como empregada doméstica porque tal registro inviabilizaria a obtenção de empregos de maior prestígio no futuro (Damasceno, 1997).

Marta Machado e Márcia Lima (2015), analisando os marcadores de gênero e raça no documentário Domésticas, apontam para os efeitos dessa articulação entre raça, gênero e emprego doméstico. Por um lado, há a produção de uma classe subalterna de trabalhadores e as mazelas das suas condiçóes concretas de vida; de outro, está o campo das representações sociais e da construção da imagem de subalterno, associada tanto à desvalorização do trabalho doméstico e sua tradicional atribuição à mulher, quanto às permanências escravocratas evidenciadas nas relações trabalhistas. Dessa forma, pensar em trabalho doméstico implica necessariamente levar em conta todas essas dimensões: a relação de exploração do trabalho e as relações - materiais e simbólicas - da desigualdade de raça e gênero.

Nas próximas seções analisaremos as mudanças e permanências das especificidades do emprego doméstico entre 2002-2012. Nossas perguntas-chaves são: Mudaram as principais características do emprego doméstico? Se sim, de que forma e em que intensidade? Nossa hipótese mais geral é que as mudanças ocorridas no país nesse período contribuíram para uma alteração do perfil do emprego doméstico, independentemente das mudanças internas da própria ocupação. 


\section{Perfil e mercado de trabalho: tendências recentes}

Nesta seção apresentamos os dados sobre emprego doméstico no Brasil, utilizando as dimensões consideradas pertinentes pela literatura especializada. Em primeiro lugar, é preciso ter ciência do tamanho deste grupo. Segundo os dados da PNAD ${ }^{4}$, 5.239.867 pessoas eram empregadas domésticas no ano de 2012; em 2002, esse número era 5.520.421, representando uma redução de 280.554 ao longo do período. Historicamente, esta sempre foi uma ocupação numerosa no Brasil e, apesar de sua contínua redução, ainda representa 5,5\% das pessoas ocupadas no país. Porém, se compararmos com o tamanho deste grupo nos anos 1990, a redução é ainda mais significativa, pois já foram mais de 7 milhões de empregados domésticos, correspondendo a cerca de 7,0\% dos ocupados. Os empregados domésticos permanecem como uma categoria marcada pela baixa escolaridade, com predominância da população negra e majoritariamente feminina. Alguns dados, entretanto, ilustram parte das mudanças e permanências que caracterizam os trabalhadores domésticos entre os anos de 2002 e 2012.

O primeiro destaque é a permanência do caráter feminino da ocupação, que se mantém praticamente inalterada: 93,6\% em 2002 e 92,8\% em 2012. Quanto à participação por grupos de cor, a população negra (pretas e pardas), que já era maioria em 2002, apresenta um crescimento significativo: de $56,7 \%$ para $64,0 \%$, respectivamente, tornando o emprego doméstico uma ocupação ainda mais negra. Outro dado expressivo é o crescimento dos níveis de escolaridade: em 2002, 92,5\% tinham no máximo o ensino fundamental completo, ao passo que esse percentual cai para 81,8\% em 2012, embora ainda seja notável que se trata de uma ocupação com baixíssima escolaridade.

Um dos aspectos mais importantes desses dados descritivos diz respeito à mudança na composição etária desses trabalhadores, especialmente quando observamos a redução da participação das faixas mais jovens, conforme apontada pela bibliografia.

No ano de 2002, as faixas de 20 a 29, 30 a 40 e 41 a 64 anos respondiam, cada uma, por aproximadamente 30,0\% do total. O Gráfico 1 mostra como o panorama se altera substancialmente ao longo dos anos. $O$ primeiro desses grupos declina para $14,0 \%$ (uma redução de $12,6 \%$ pontos percentuais e de nada menos do que 735.204 em números absolutos). O grupo de 10 a 19 anos, que representava mais de 10,0\% do total, chega ao final da série com 4,3\% (uma redução de quase 400 mil pessoas

4. Os dados analisados referem-se à posição na ocupação "empregado doméstico". Nessa categoria estão as seguintes ocupações: caseiro, empregados domésticos nos serviços gerais, empregado doméstico arrumador, empregado doméstico faxineiro, empregado doméstico diarista, faxineiro no serviço doméstico, arrumador no serviço doméstico. 
no total). Esse dado aponta uma mudança importante para a dinâmica do emprego doméstico, pois a participação das mulheres mais jovens nessa ocupação sempre foi um aspecto que potencializa sua vulnerabilidade, na medida em que o ingresso no mercado de trabalho via trabalho doméstico implicava pouca possibilidade de mudança de trajetória.

Acreditamos que houve uma redução da taxa de reposição ao longo desses anos, o que ajuda a explicar o envelhecimento do perfil do emprego doméstico. Enquanto o grupo entre 30 e 40 anos se manteve praticamente constante (em torno de 30,0\%), a participação relativa daqueles entre 41 e 64 anos cresce de 29,9\% para 48,4\%. Em 2012, portanto, $80,0 \%$ do total de trabalhadores domésticos no país tinham mais do que 30 anos, percentual que era de 60,0\% em 2002. O envelhecimento, como bem se pode notar, se deu às custas da redução da participação das mais jovens (10 a 19 e 20 a 29 anos) nesse segmento: podendo adiar a entrada no mercado de trabalho para permanecerem na escola, elas tendem a reduzir sua entrada nessa ocupação, aspecto já assinalado por alguns autores (Barros et al., 2000).

\section{GRÁFICO 1}

\section{Composição do emprego doméstico no Brasil segundo faixas etárias; 2002-2012}

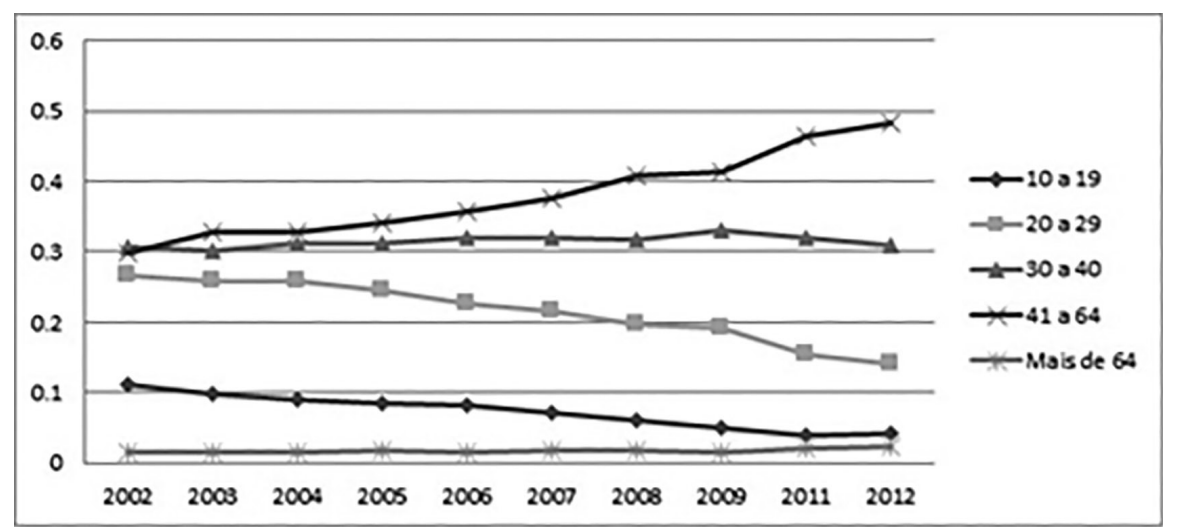

Fonte: Pesquisa Nacional de Amostra por Domicílio, 2002 a 2012.

As mudanças no mercado de trabalho também são expressivas. De um modo geral, e seguindo a tendência do mercado ao longo da década de 2000, é possível observar um forte incremento das taxas de formalização e dos salários reais. Novamente utilizando os dados das PNADs de 2002 a 2012, comparamos a taxa de formalização das domésticas com as taxas de formalização da média nacional ${ }^{5}$. Para o total de trabalhadores essa taxa era de $43,7 \%$ em 2002 e chega a 61,4\% em 2012,

5. Por questões de espaço, esses dados não são apresentados no texto em forma de gráfico ou tabela. Caso seja de interesse, o leitor pode solicitá-los aos autores por correspondência eletrônica. 
com um crescimento de 14,1 pontos percentuais ${ }^{6}$. Para os trabalhadores domésticos, esse crescimento foi de 9,5 pontos percentuais (28,4\% em 2002 contra 37,9\% em 2012). Entretanto, se observarmos a taxa de crescimento do emprego formal, vemos um cenário completamente distinto. Enquanto para a média nacional essa taxa foi de $26,6 \%$, para os trabalhadores domésticos foi de 55,7\%. Dessa forma, e embora os resultados ainda sejam inconclusivos para o impacto de medidas legais de incentivo à formalização - como a redução dos encargos trabalhistas da lei 11.324 de 2006 (Theodoro e Scorzafave, 2011) -, os trabalhadores domésticos se beneficiaram em maior magnitude do aumento da formalização no mercado de trabalho ao longo do período 2002-2012.

A clivagem entre formal e informal ainda é um forte determinante das diferenças salariais. A média do rendimento dos trabalhadores domésticos formais, que era de $\mathrm{R} \$ 524,00$ no primeiro ano analisado, sobe para $\mathrm{R} \$ 747,00$ em 2012 (valores atualizados em reais de 2014). Para os informais, estas cifras são de $\mathrm{R} \$ 319,00$ e $\mathrm{R} \$ 470,00$, respectivamente. Por outro lado, os ganhos reais para ambos os grupos são significativos, de 47,0\% para os informais e de 52,0\% para os trabalhadores formais. Kênia de Souza e Edson Domingues (2014) estimam que esse crescimento do rendimento do emprego doméstico tem diversos impactos indiretos na dinâmica da geração de empregos e do consumo das famílias. Segundo esses autores, entre 2006 e 2011 , tal crescimento responde pela criação de 660 mil postos indiretos de trabalho, ao mesmo tempo que por $6,61 \%$ do consumo das famílias pertencentes ao primeiro decil da distribuição de renda per capita.

De um modo geral, esses primeiros dados deixam entrever que o cenário do emprego doméstico foi marcado por tendências diversas ao longo do período. Em relação ao mercado de trabalho, as mudanças seguem, ainda que com especificidades, o padrão do cenário nacional de formalização e aumento dos salários ao longo da década de 2000 .

Quando nos aprofundamos nas mudanças de perfil dessa ocupação, há dois pontos que merecem destaque. Em primeiro lugar, a manutenção de características históricas que marcam a ocupação, como a baixa escolaridade e a maior presença de negros e mulheres. Por outro lado, e esta é certamente a principal mudança observada no período, houve uma profunda alteração na composição etária. Os jovens de até 29 anos reduzem drasticamente a sua participação relativa. Mais do que uma simples mudança de perfil etário, este resultado nos faz indagar sobre a posição do emprego doméstico no conjunto do mercado de trabalho e, consequentemente, das possibilidades que podem ter se aberto para as gerações mais jovens em virtude de

6. Consideramos formalização: empregados com carteira assinada, estatutários, membros do exército, empregadores e contribuintes de instituto de previdência. 
mudanças estruturais do mercado de trabalho e no sistema educacional, aspecto que será aprofundado na próxima seção.

Consideramos todas as questões acima abordadas, resta-nos ainda um último ponto. Ao nos debruçarmos sobre o perfil, destacamos características daquilo que é comum ao grupo. Há, entretanto, um aspecto raramente abordado no tema, qual seja, a heterogeneidade interna do emprego doméstico a partir das suas principais clivagens.

Para identificar essa heterogeneidade, utilizamos uma análise de conglomerados (cluster analysis) realizada para o conjunto dos trabalhadores domésticos nos dois pontos extremos da série (2002 e 2012). Para a caracterização dos grupos, utilizamos as principais dimensões sociodemográficas e do mercado de trabalho identificadas pela literatura como importantes para a caracterização deste grupo ${ }^{7}$ : (i) nível educacional; (ii) idade; (iii) raça; (iv) taxa de formalização; (v) rendimento na ocupação principal; (vi) situação censitária do domicílio de residência (rural; urbano não metropolitano; metropolitano); (vii) região do país.

O resultado da análise de cluster identificou três grupos principais:

- Um grupo mais vulnerável: que se caracteriza por ser mais jovem, mais negro e menos escolarizado, com menores salários e menos formalizado. Está mais presente no Nordeste, em municípios urbanos não metropolitanos e áreas rurais.

- Um grupo menos vulnerável: mais velho, mais branco, mais escolarizado, com maiores salários e níveis de formalização. Está mais concentrado nas regiões metropolitanas e no Sudeste.

- Encontramos ainda um grupo intermediário que apresenta características que ora se aproximam do grupo mais vulnerável ora se aproximam do outro grupo, a depender da dimensão privilegiada.

Estes resultados demonstram que, apesar da heterogeneidade, há uma manutenção das clivagens históricas de reprodução de desigualdades em dois sentidos distintos. Em primeiro lugar, os atributos individuais daqueles que estão mais propensos a se inserirem no emprego doméstico e não em outros segmentos do mercado de trabalho, como o perfil geral desses trabalhadores já apontava. Em segundo, podemos observar também marcadores sociais de diferenças que se reproduzem mesmo no interior do grupo de trabalhadores domésticos.

7. O principal objetivo da análise de cluster é a identificação, dentro de um grupo maior, de grupos menores que sejam internamente homogêneos e diferentes uns dos outros. Justamente por isso, optamos por não incluir a variável "sexo", visto que ela não teria nenhum efeito para diferenciar os indivíduos em grupos distintos devido ao fato de mais de $90,0 \%$ dos trabalhadores domésticos serem mulheres. Mais detalhes da análise de cluster e dos seus resultados podem ser solicitados para os autores. 
QUADRO 1

Caracterização dos grupos segundo variáveis selecionadas

\begin{tabular}{c|c|c|c} 
Dimensão & Inferior & Médio & Superior \\
\hline Educação & Menos & Médio & Mais \\
Idade & Mais jovem & Mais velho & Mais velho \\
Situação Censitária & Urbana & Dividido & Metropolitana \\
Raça & Negro & Dividido & Branco \\
Região & Nordeste & Sudeste & Sudeste \\
Formalização & Baixo & Médio & Médio \\
Renda & Menor & Intermediário & Maior \\
\hline Tamanho 2002 & $77.7 \%$ & $20.1 \%$ & $2.2 \%$ \\
Tamanho 2012 & $69.7 \%$ & $27.2 \%$ & $3.0 \%$
\end{tabular}

Fonte: Elaboração dos autores a partir dos resultados da análise de cluster.

Uma análise mais detalhada desses três grupos demonstra que a renda do grupo superior (menos vulnerável) é praticamente o dobro da renda do grupo intermediário e aproximadamente quatro vezes a renda do grupo inferior, como mostra o Quadro A1 no anexo. Em termos educacionais, as diferenças também são significativas: 30,0\% dos trabalhadores do grupo superior tinham completado o ensino médio no ano de 2012, ao passo que esse percentual é de 19,6\% e 15,8\% para os dois outros grupos, respectivamente. O grupo inferior é também aquele marcado pela maior presença de negros e jovens de até 29 anos.

É importante, contudo, destacar o tamanho relativo dos grupos. Por um lado, a predominância do grupo inferior (77,7\% em 2002 e 68,5\% em 2012) e intermediário (20,0\% em 2002 e 28,3\% em 2012) evidencia uma situação de relativa estabilidade e mostra que a vulnerabilidade é a marca da esmagadora maioria dos trabalhadores domésticos. Por outro, as mudanças não são desprezíveis. O grupo intermediário cresceu quase 9 pontos percentuais, quase a mesma intensidade do declínio do grupo inferior, ao passo que o grupo superior teve um incremento de 2,2\% para 3,3\%.

Tomados os resultados em conjunto, três aspectos sobressaem. Em primeiro lugar, o relativo grau de heterogeneidade do emprego doméstico, tal como já ressaltamos, é um achado importante para pensar formas de melhorar as condições do emprego doméstico. Em segundo, as clivagens internas que constituem os próprios parâmetros de diferenciação e proporcionam a heterogeneidade interna ao grupo de trabalhadores domésticos como um todo. Ou seja, os marcadores sociais que configuram o perfil das empregadas domésticas funcionam dentro do próprio 
grupo como marcadores de diferenciação. Em terceiro, é significativa a melhoria observada da situação relativa de todos os grupos, o que se evidencia especialmente no crescimento dos grupos intermediário e superior.

Um último aspecto a ser destacado refere-se ao peso relativo de cada uma das dimensões para a classificação dos grupos. Tanto em 2002 quanto em 2012, a renda do trabalho e a formalização foram as variáveis que mais determinaram o padrão de agrupamento. Isso significa que as principais clivagens internas ao grupo de trabalhadores domésticos se referem ao modo de inserção ocupacional, como era de se esperar. Entretanto, no ano de 2002, a terceira mais importante era a região; em 2012 passou a ser a situação censitária. Esse resultado demonstra uma transição da diferenciação das grandes regiões para as dimensões urbanas e metropolitanas.

Mais instigante que isso, contudo, é o fato de que a idade, que em 2002 era o sexto determinante, passa a ser o quarto em 2012. Isto significa que a mudança na estrutura etária das empregadas domésticas torna-se um dos principais mecanismos de heterogeneidade dessa ocupação. O Gráfico 1 já apontava para o declínio sistemático, e bastante significativo, da participação dos mais jovens nesse segmento.

Com base nesses resultados, optamos por observar com mais acuidade algumas características das mulheres de 20 a 29 anos, pouco escolarizadas e que em 2002 constituíam uma parcela expressiva das empregadas domésticas, a qual apresentou a maior redução de participação entre 2002 e 2012. Na próxima seção buscaremos identificar para onde essas mulheres se deslocaram.

Novas portas de entrada no mercado trabalho?

Para explorar o ponto aventado na seção anterior, observaremos as principais mudanças ocupacionais entre o grupo de mulheres de 20 a 29 anos com até o ensino fundamental completo, justamente o grupo educacional que se mostrou o mais expressivo entre as domésticas dessa faixa etária no ano de 2002 e que apresentou uma forte redução em $2012^{8}$. Com o intuito de identificar se essas mudanças atingem de forma distinta as mulheres brancas e negras, os dados foram analisados segundo cor/ raça. O objetivo é verificar quais foram as ocupações que mais cresceram e aquelas que mais diminuíram entre as mulheres brancas e negras que, a título de exercício, poderíamos chamar de "potenciais domésticas". Os quadros a seguir trazem os resultados.

8. Embora o emprego doméstico se defina a partir da posição na ocupação, os dados referentes ao emprego doméstico apresentados nesta seção referem-se à Classificação Brasileira de Ocupações, de modo a proporcionar uma comparação mais confiável com as demais categorias ocupacionais. 
QUADRO 2

Ocupaçôes com maior declinio de participação relativa entre as mulheres de 20 e 29 anos com até ensino fundamental completo, segundo cor/raça; 2002-2012

\begin{tabular}{|c|c|c|c|c|c|c|c|c|}
\hline $8 \times a$ & Qvacoles.c804firibs & $\mathrm{N} \times \mathrm{O} 2$ & $x 0 \%$ & Non & 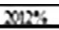 & Sibs & Sido\% & Pendintion Xal \\
\hline \multirow{11}{*}{ Bnesers } & 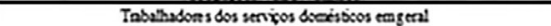 & $5+1100$ & 123 & $2002 m$ & 5,4 & .306078 & .59 & 50,0 \\
\hline & Ta buhadxes agócols por coeta propes & insts & 46 & $\$ \times 52$ & 23 & .10493 & .23 & $x+8$ \\
\hline & 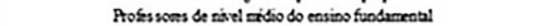 & 100207 & 25 & 1226 & 3 & $\$ 93 !$ & .21 & 6470 \\
\hline & Vinodediens antochates & Esil & 1,7 & $1726 !$ & 5 & .5000 & $.1,2$ & $\$ 10$ \\
\hline & Trbubudoes ruras de sublistroxia & 100065 & 25 & 50615 & is & $-20+50$ & $-1,0$ & 710 \\
\hline & 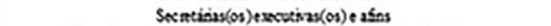 & $4 \$ 16$ & 12 & $\$ 037$ & 1 & tans & $.1,0$ & $2 \pm 5,0$ \\
\hline & 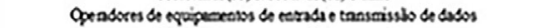 & 12076 & 3,4 & \$SOO: & 26 & - & $-0,8$ & $\$ \$ 0,0$ \\
\hline & Tabasusber satropecuirios eaferal & 26572 & 1,1 & 8720 & 2 & 37532 & .09 & $\$ 50$ \\
\hline & 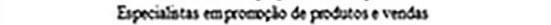 & S:14 & 1,4 & $\$ 0 \times 6$ & .8 & 2005 & $-0,5$ & 1183,0 \\
\hline & 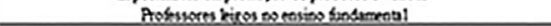 & $x$ & 6 & $20 \%$ & 1 & 2489 & .06 & $\$ 180$ \\
\hline & Wha de Rood 2002 & \multicolumn{7}{|c|}{2090} \\
\hline \multirow{11}{*}{ Vegros } & 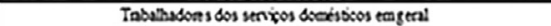 & 99002 & 226 & anst & 11,0 & .319735 & .116 & 450 \\
\hline & 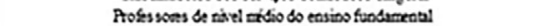 & 100107 & 29 & 23064 & 3 & .3543 & .24 & 800 \\
\hline & Veodedoes anbobates & 123334 & 3,5 & 5009 & 12 & 72200 & .23 & 3630 \\
\hline & Tabusaboes agropecuirios engeral & $\$ 1815$ & 23 & 15155 & 3 & $\$ 8060$ & .20 & \$1,0 \\
\hline & Tabahsdseres agcicois por conta propis & 2002 & 6,4 & 180008 & 42 & _ost & .22 & $\$ 940$ \\
\hline & Trabshadons ruras de sobsisteocia & 199317 & As & $20: 6$ & 28 & woss & $.1,7$ & $\$ 18$ \\
\hline & Professores kitros so ensios sodierental & wass & $\$$ & $\gamma 15$ & 2 & 21650 & $-0,6$ & 730 \\
\hline & Contervos & 1990 & 5 & 1623 & 0 & .63:6 & 0.5 & 510 \\
\hline & 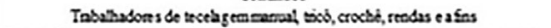 & 17251 & s & 453 & 1 & .12693 & $-0,4$ & 925 \\
\hline & 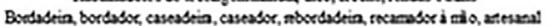 & $m$ m & 4 & 2203 & $i$ & $.007 !$ & $-0,3$ & 200 \\
\hline & 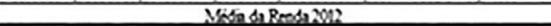 & \multicolumn{7}{|c|}{5390} \\
\hline
\end{tabular}

Fonte: PNADs, 2002 e 2012.

QUADRO 3

Ocupaçôes com maior aumento de participação relativa entre as mulheres de 20 e 29 anos com até ensino fundamental completo, segundo cor/raça; 2002-2012

\begin{tabular}{|c|c|c|c|c|c|c|c|c|}
\hline $5 \times 1$ & 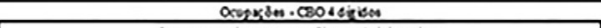 & $\times 300$ & 20056 & N:S012 & 20154 & 560 & 5,604 & $8 \operatorname{mos} \cos x \times 12$ \\
\hline \multirow{11}{*}{ Sances: } & 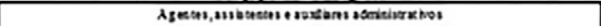 & 2 2): & 38 & म7म & (0) & $150 \%$ & 4 & 10038 \\
\hline & 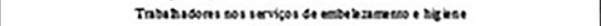 & พะฒ & 23 & 2006 & 45 & 7044 & 22 & 946 \\
\hline & Secpibeitar & $: 0 \times: 0$ & 3 & axes & 5,2 & sas: & is & $20: 8$ \\
\hline & 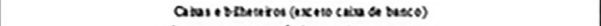 & $130 \%$ & 32 & $\mathrm{mos}$ & 47 & $\infty 2$ & 18 & 5928 \\
\hline & 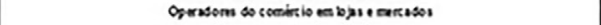 & s): & 128 & 5:4t & (5) & $4: 28$ & is & thes \\
\hline & Opeasomi ce teitrariatiag & 30104 & 3 & taro & 2,1 & \&42 & 12 & tas \\
\hline & 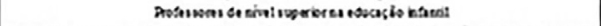 & $2=4$ & $\therefore$ & $200 \%$ & 1,0 & mow & QP & (as? \\
\hline & 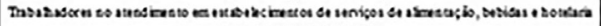 & 9722 & is & nam & 2,6 & $\pm+\infty$ & 0,7 & s:p \\
\hline & Avoum a coectibase & 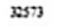 & 8 & 4002 & 13 & เ & os & 1wso \\
\hline & 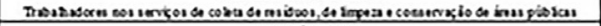 & as:i & is & $70 \times 0$ & 20 & $200 \%$ & OS & 6130 \\
\hline & Bossidiga.012 & \multicolumn{7}{|c|}{$\sin 0$} \\
\hline \multirow{11}{*}{ Nopros } & 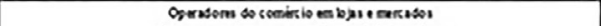 & $3 \times 0 \%$ & DS & smis & 142 & 2क112 & 4 & 7280 \\
\hline & 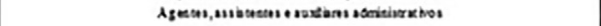 & :osst & 2 & stsi: & 5,0 & 15654 & 31 & क:,? \\
\hline & 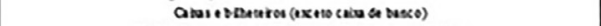 & $\$ 414$ & 24 & m.น & 40 & ברנו & 22 & 7528 \\
\hline & 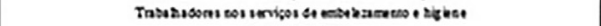 & แan & 3. & 2100 & s,2 & 12018 & is & 0000 \\
\hline & Socopietival & no3s & 23 & sosss & 3,9 & 5422 & 18 & 9078 \\
\hline & 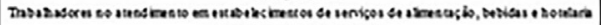 & $72: 4$ & 2 & stomo & 2,6 & sos & is & Q\$\%, \\
\hline & Opeasenes de teherarbeting & :s4:s & 3 & mi & 2,4 & cass & 1,4 & 7308 \\
\hline & costement & coses & is & מm & 2.8 & sspos & $Q$ & 0008 \\
\hline & 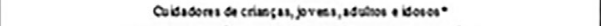 & Tous & 22 & LNSto & 2,2 & 4005 & 0,5 & $\operatorname{sos} 8$ \\
\hline & 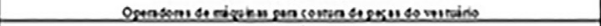 & $\cos$ & is & 2000 & 32 & $\mathrm{~N}+3 \mathrm{Z}$ & os & asp \\
\hline & Soniviande & & & & & & & \\
\hline
\end{tabular}

Fonte: PNADs, 2002 e 2012.

Os resultados são mais do que expressivos. Considerando as jovens de 20 a 29 anos com até o ensino fundamental completo, temos um saldo negativo de nada menos do que 626.616 domésticas entre 2002 e 2012. Isso indica que o peso da atividade doméstica declinou fortemente nesse grupo etário ao longo dos anos. Para as mulheres brancas, a queda relativa foi de $60,0 \%$, enquanto que para as mulheres negras esse percentual foi de 40,0\%. Em pontos percentuais, essas quedas foram de 6,9\% e $11,6 \%$, respectivamente. Embora a taxa do declínio do emprego doméstico entre as mulheres brancas tenha sido maior quando levamos em conta o número absoluto de postos de trabalho nos quais cada um dos grupos se insere, a queda da participação do emprego doméstico entre as ocupadas foi maior entre o grupo de mulheres negras. 
Poder-se-ia argumentar que essa queda dos números absolutos é fruto de uma questão simplesmente demográfica, tendo em vista que, em 2002, o grupo de jovens de 20 a 29 anos com este nível educacional era superior a 2012. Entretanto, os números percentuais indicam que não é esse o caso. Em 2002, 10,4\% das jovens pertencentes a esse grupo etário encontrava-se no emprego doméstico, ao passo que em 2012 esse percentual é de 6,1\%, uma queda de mais de 4,0\% no total. Além disso, se fosse um fator demográfico, não seria possível exemplificar o crescimento dos números absolutos nas outras ocupações, conforme demonstrado no Quadro 3.

Há razões suficientes para crer que a mudança no perfil do emprego doméstico, em especial se considerarmos o grupo de jovens menos qualificadas, deveu-se em grande medida a uma expansão dos setores do mercado de trabalho urbano. Mais do que isso, pelo crescimento de ocupações qualitativamente superiores, seja do ponto de vista dos rendimentos ou do acesso a direitos decorrente de maiores níveis de formalização. Se em 2002 o emprego doméstico se afigurava como uma das principais opções de inserção ocupacional para essas jovens, em 2012 o cenário é bastante distinto, permitindo afirmar que elas tiveram, ao longo desses dez anos, acesso a melhores postos na estrutura ocupacional.

Ao observar tais tendências segundo raça/cor, destaca-se que há uma semelhança das ocupações que mais cresceram tanto para mulheres negras quanto para as mulheres brancas, especialmente nas ocupações no setor de serviços, como auxiliares administrativas, trabalhadoras nos serviços de embelezamento e higiene e operadoras do comércio em lojas e mercados. Entretanto, as desigualdades raciais são bastante expressivas no que diz respeito ao rendimento do trabalho, ainda que inseridas nas mesmas ocupações. Considerando as mulheres inseridas no emprego doméstico, a diferença salarial é de $17 \%$ em favor das brancas.

Entre as ocupações que mais cresceram, as desigualdades raciais se mantêm. Por exemplo, as mulheres negras inseridas na ocupação de serviços de embelezamento e higiene recebem $73 \%$ da renda média das brancas. Entre as trabalhadoras no atendimento em estabelecimentos de serviços de alimentação, bebidas e hotelaria, esse percentual é de $68 \%$. Considerando a média de todas essas ocupações deste grupo, as mulheres negras recebem $81 \%$ dos rendimentos das mulheres brancas. Em suma, fica claro que as mudanças no mercado de trabalho para as jovens menos qualificadas foram benéficas para os dois grupos, mas com intensidade maior para as mulheres brancas.

\section{Considerações finais}

O tema do emprego doméstico tem sido interpretado à luz da articulação de classe, raça e gênero, marcadores sociais que historicamente atuam na reprodução das 
desigualdades sociais construindo um estigma tanto da ocupação quanto dos seus trabalhadores perfil. O serviço doméstico não só marca um lugar na estrutura ocupacional, mas também se diferencia pelo tipo de atividade exercida e pelo espaço onde é realizada: o ambiente privado.

Entender de forma aprofundada as condições dessa ocupação traz três implicações principais. Em primeiro lugar, permite situar o emprego doméstico numa estrutura de desigualdades raciais e de gênero marcada por vetores de diferenciação que ora se aproximam e ora se distanciam no tempo e também no interior do sistema de estratificação. Em segundo, possibilita mapear se houve melhorias para esse grupo, e em que dimensão. E, em terceiro, permite averiguar em que medida essas mudanças são convergentes com movimentos mais gerais de aumento e declínio de desigualdades.

Neste artigo, percebemos que o serviço doméstico se reproduz na estrutura ocupacional como o mais mal remunerado, menos qualificado e predominantemente negro e feminino. Ao mesmo tempo demonstramos que, longe de um cenário ideal, a tendência, no período analisado, foi o emprego doméstico apresentar uma melhora substantiva das condições da ocupação, consoante com a melhoria da maior parte dos indicadores do mercado de trabalho e de redução das desigualdades ao longo do período.

Um resultado que ainda precisa ser mais explorado no futuro diz respeito à heterogeneidade do emprego doméstico. Em primeiro lugar, observamos que, a despeito da predominância das características tradicionais do emprego doméstico no Brasil, as velhas conhecidas clivagens que são tomadas para caracterizar esse grupo como unidade, porque típico, também o perpassam internamente, produzindo níveis distintos de vulnerabilidade nesse segmento do mercado de trabalho. Isso provoca justamente a necessidade de melhor compreender o que há de específico nos seus mecanismos de operação quando no interior do emprego doméstico, além da forma que assumem nas diferentes interações cotidianas e nas construções simbólicas sobre a ocupação e suas características.

Nossos dados demonstram ainda que as mulheres de 20 a 29 anos que completaram no máximo o ensino fundamental reduziram fortemente sua participação nessa ocupação. Ao mapearmos tal mudança, percebemos que houve um deslocamento para outras ocupações do baixo terciário, de maior rendimento e com maior acesso a direitos (porque mais formalizadas). Por outro lado, a intensidade da mudança foi marcada por uma forte clivagem racial.

O cenário atual de redução de direitos pode afetar de forma profunda um grupo que começou apenas no século XXI a melhorar suas condições no mercado de trabalho, permanecendo ou saindo dessa ocupação. Por um lado, boa parte da melhora do emprego doméstico se deu em função da melhora generalizada do mercado de 
trabalho no período. Mas, por outro, é imperativo ter em mente que, para além de conjunturas econômicas mais ou menos favoráveis, os arranjos institucionais que se traduzem no sistema de proteção social podem atuar como impulsionadores ou mitigadores de um possível quadro reversivo das condições do emprego doméstico, que se instalou a partir de 2015.

Dessa forma, se é certo que a diminuição da cesta de benefícios que acompanha o trabalho formal e o aumento da assimetria de poder entre empregados e empregadores são medidas que afetam negativamente a maior fatia do mercado de trabalho, também é certo que atingem de forma desproporcional os mais desprivilegiados, especialmente os trabalhadores domésticos. Considerando as mudanças já aprovadas, como o congelamento dos gastos nos próximos vinte anos e as alterações na regulação do trabalho, em especial a aprovação da lei da terceirização, e as mudanças que estão por vir, como a Reforma Previdenciária, os poucos ganhos abordados neste artigo certamente não serão consolidados. O emprego doméstico continuará na invisibilidade.

\section{Referências Bibliográficas}

Angelin, Paulo \& Truzzi, Oswaldo. (2015), "Patroas e adolescentes trabalhadoras domésticas: Relações de trabalho, gênero e classes sociais". Revista Brasileira de Ciências Sociais, 30 (89): 63-76.

Barros, R. P. B.; Mendonça, R.; Deliberalli, P. \& Bahia, M. (2000), “O trabalho doméstico infantojuvenil no Brasil”. Nota Técnica Ipea. Brasília, pp. 1-10.

Bernardino-Costa, Joaze. (2015), "Decolonialidade e interseccionalidade emancipadora: a organização política das trabalhadoras domésticas no Brasil”. Sociedade e Estado. Brasília, 30 (1): 147-163.

Bruschini, Cristina; Lombardi, Maria Rosa. (2000). "A bipolaridade do trabalho feminino no Brasil contemporâneo”. Cadernos de Pesquisa, 110: 67-104.

Carneiro, Sueli \& Santos, Thereza. (1995), Mulher negra. São Paulo, Nobel.

Burnham, Linda \& Theodore, Nik. (2012), Home economics: the invisible and unregulated world of domestic work. Nova York, National Domestic Worker Alliance, Center for Urban Economic Development, University of Illinois at Chicago.

Damasceno, Caetana M. (1997), “Trabalhadoras cariocas: algumas notas sobre a polissemia da boa aparência”. Estudos Afro-Asiáticos, 31: 125-150.

Hasenbalg, Carlos \& Silva, Nelson do Vale. (1998), Estrutura social, mobilidade e raça. São Paulo/Rio de Janeiro, Vértice/Iuperj.

IPEA. (2013), "Um retrato de duas décadas do mercado de trabalho brasileiro utilizando a 
PNAD". Comunicados Ipea, 160: 1-31. Disponível em http://www.ipea.gov.br/portal/images/ stories/PDFs/comunicado/131007_comunicadoipea160.pdf.

Lima, Márcia \& Silva, Denise. (1992), “Raça, gênero e mercado de trabalho”. Estudos Afro-Asiáticos, 23: 97-113.

Orт. (2010), Trabalho doméstico no Brasil: rumo ao reconhecimento institucional. Brasília, Organização Internacional do Trabalho/Escritório Brasil.

Pinheiro, Luana; Gonzales, Roberto \& Fontoura, Natália. (2012), Expansão dos direitos das trabalhadoras domésticas no Brasil. Nota Técnica. Brasília, Ipea.

Pinheiro, Luana; Fontoura, Natália \& Pedroza, Cláudia. (2011), “Situação atual das trabalhadoras domésticas no país". In: Bernardino-Costa, Joaze; Figueiredo, Angela \& CRUz, Tânia (orgs.). A realidade do trabalho doméstico na atualidade. Brasília, Centro Feminista de Estudos e Assessoria.

Rezende, Cláudia \& Lima, Márcia. (2004), “Linking gender, class and race in Brazil”. Social Identities, 10 (6): 757-773.

Rosemberg, Fulvia. (1994), “A educação de mulheres jovens e adultas”. In: SAFfiot, Heleieth \& VArgas, Monica. Mulher brasileira é assim. Rio de Janeiro/Brasília, Rosa dos Tempos/ Nipas/Unicef.

Saffioti, Heleieth. (1979), Emprego doméstico e capitalismo. Petrópolis, Vozes.

Souza, Kenia; Domingues, Edson. (2014), "Mudanças no mercado de serviços domésticos: uma análise da evolução dos salários no período 2006-2012”. Economia Aplicada, 18 (2): 319-346.

Theodoro, Maria Isabel Accoroni \& Scorzafave, Luís Guilherme. (2012), “Impacto da redução dos encargos trabalhistas sobre a formalização das empregadas domésticas". Revista Brasileira de Economia, 65 (1): 93-109.

Tilly, Charles. (1998), Durable inequality. Califórnia, University of California Press.

VIDAL, Dominique. (2009), "Empleo domestico, normas jurídicas y sociedad democrática en Brasil". In: Araujo, Kathya (ed.). Se acata pero no se cumple? Estudios sobre las normas en America Latina. Santiago do Chile, Lom Ediciones. 
Anexo

QUADRO A1

Caracteristicas dos grupos, segundo variáveis selecionadas

\begin{tabular}{|c|c|c|c|c|c|c|c|c|c|c|c|}
\hline \multicolumn{12}{|c|}{2002} \\
\hline & \multicolumn{5}{|c|}{ Educaşăo } & \multicolumn{5}{|c|}{ Idade } & \multirow{2}{*}{\begin{tabular}{|c|} 
M. T. \\
Formalizaş3o
\end{tabular}} \\
\hline & Analf. & F.I. & F.C. & M.C. & S.C. & $10 \cdot 19$ & $20 \triangle 29$ & 30,40 & 41 a 64 & $\begin{array}{c}\text { mais de } \\
64\end{array}$ & \\
\hline Inferior & $11.2 \%$ & $66.0 \%$ & $16.0 \%$ & $6.8 \%$ & $0.0 \%$ & $13.9 \%$ & $28.6 \%$ & $28.7 \%$ & $27.2 \%$ & $1.6 \%$ & $20.9 \%$ \\
\hline Intermediário & $7.7 \%$ & $63.9 \%$ & $18.8 \%$ & $9.6 \%$ & $0.0 \%$ & $1.6 \%$ & $19.6 \%$ & $37.8 \%$ & $40.0 \%$ & $1.0 \%$ & $55.6 \%$ \\
\hline \multirow[t]{2}{*}{ Superior } & $7.7 \%$ & $65.8 \%$ & $17.1 \%$ & $9.4 \%$ & $0.0 \%$ & $0.0 \%$ & $16.6 \%$ & $33.8 \%$ & $47.8 \%$ & $1.8 \%$ & $58.7 \%$ \\
\hline & Rural & Urb & Met & Negro & Branco & Norte & Nordeste & Sudeste & Sul & $\begin{array}{c}\text { Centro- } \\
\text { Oeste }\end{array}$ & Renda Média \\
\hline Inferior & $11.1 \%$ & $63.7 \%$ & $25.1 \%$ & $59.6 \%$ & $40.4 \%$ & $6.9 \%$ & $28.5 \%$ & $41.9 \%$ & $13.7 \%$ & $9.0 \%$ & 283.82 \\
\hline Intermediário & $6.5 \%$ & $41.3 \%$ & $52.1 \%$ & $47.8 \%$ & $52.2 \%$ & $1.6 \%$ & $4.3 \%$ & $68.8 \%$ & $17.8 \%$ & $7.6 \%$ & 652.22 \\
\hline Superior & $3.6 \%$ & $23.9 \%$ & $72.5 \%$ & $43.5 \%$ & $56.5 \%$ & $0.3 \%$ & $1.8 \%$ & $74.2 \%$ & $18.9 \%$ & $4.9 \%$ & 1259.33 \\
\hline \multicolumn{12}{|c|}{2012} \\
\hline & \multicolumn{5}{|c|}{ Educoşão } & \multicolumn{5}{|c|}{ Idade } & M. T. \\
\hline & Analf. & F.I. & F.C. & M.C. & s.c. & 10 a 19 & $20 \times 29$ & 30,40 & 41 a 64 & $\begin{array}{c}\text { mais de } \\
64\end{array}$ & formalizşృ \\
\hline Inferior & $13.4 \%$ & $49.4 \%$ & $20.8 \%$ & $15.8 \%$ & $0.5 \%$ & $5.9 \%$ & $16.1 \%$ & $30.5 \%$ & $45.0 \%$ & $2.5 \%$ & $20.3 \%$ \\
\hline Intermediário & $8.6 \%$ & $46.1 \%$ & $24.1 \%$ & $19.6 \%$ & $1.5 \%$ & $0.6 \%$ & $9.6 \%$ & $32.6 \%$ & $55.4 \%$ & $1.8 \%$ & $50.4 \%$ \\
\hline \multirow[t]{2}{*}{ Superior } & $7.5 \%$ & $39.9 \%$ & $21.7 \%$ & $29.0 \%$ & $1.9 \%$ & $0.7 \%$ & $8.3 \%$ & $31.7 \%$ & $57.2 \%$ & $2.1 \%$ & $45.1 \%$ \\
\hline & Rural & Urb & Met & Negro & Branco & Norte & Nordeste & Sudeste & Sul & $\begin{array}{c}\text { Centro- } \\
\text { Oeste }\end{array}$ & Renda Média \\
\hline Inferior & $11.9 \%$ & $61.6 \%$ & $26.5 \%$ & $68.8 \%$ & $31.2 \%$ & $9.1 \%$ & $33.3 \%$ & $38.7 \%$ & $10.9 \%$ & $8.0 \%$ & 417.83 \\
\hline Intermediśrio & $5.4 \%$ & $47.7 \%$ & $46.9 \%$ & $55.2 \%$ & $44.8 \%$ & $2.6 \%$ & $5.5 \%$ & $62.5 \%$ & $19.7 \%$ & $9.7 \%$ & 843.12 \\
\hline Superior & $6.5 \%$ & $40.1 \%$ & $53.4 \%$ & $49.1 \%$ & so. $9 \%$ & $1.5 \%$ & $3.9 \%$ & $62.6 \%$ & $23.7 \%$ & $8.4 \%$ & 1580.42 \\
\hline
\end{tabular}

Fonte: Elaboração a partir da análise de cluster. Dados das PNADs, 2002 e 2012. 


\section{Resumo}

Emprego doméstico e mudança social: reprodução e heterogeneidade na base da estrutura ocupacional brasileira

O objetivo do presente artigo é analisar mudanças no perfil das empregadas domésticas entre 2002 e 2012 considerando não apenas as alterações pontuais na legislação que antecedeu à PEC das domésticas, mas também as transformações sociais ocorridas na base da pirâmide social brasileira. Apesar da reprodução das clivagens de raça e classe que definem o perfil geral dessas trabalhadoras, o artigo demonstra que esses marcadores operam também na diferenciação interna dessa ocupação. Além disso, os dados analisados demonstram que as mudanças na base da estrutura ocupacional e no perfil educacional da força de trabalho foram decisivas para o modo como o perfil do emprego doméstico se alterou ao longo do período.

Palavras-chave: Emprego doméstico; Desigualdades raciais; Raça e gênero.

\section{Abstract}

Domestic employment and social change: reproduction and heterogeneity at the bottom of the Brazilian occupational structure

The objective of this article is to analyze changes in the profile of domestic workers (2002-2012) considering not only the distinct variations in the legislation that preceded the Project of the Constitutional amendment but also the social transformations that took place at the base of the Brazilian social pyramid. Despite the reproduction of race and class cleavages that define the general profile of these workers, the article demonstrates that these markers also operate in the internal differentiation of this occupation. Moreover, the data analyzed show that the changes in the base of the occupational structure and the educational profile of the labor force were decisive for the way the pattern of domestic employment changed over the period.

Keywords: Domestic employment; Racial inequalities; Race and gender.

Texto recebido em 24/8/2018 e aprovado em 14/1/2019.

DOI: 10.11606/0103-2070.ts.2019.149291

MÁRCiA Lima é professora do Departamento de Sociologia da FFLCH-USP e pesquisadora sênior do Cebrap.E-mail:m.rlima@uol.com.br.

Ian Prates é doutor em Sociologia pelo Programa de Pós-Graduação em Sociologia da FFLCH-USP e pesquisador do Cebrap. E-mail: ianprca@yahoo.com.br. 